\title{
Research Communication Unexpected Smoking-Linked High MMP-9 in Induced Sputum of Hazardous Dust-Exposed Workers
}

\author{
Yehuda Lerman, ${ }^{1,2}$ Abraham Moscovich, ${ }^{1,2}$ and Elizabeth Fireman ${ }^{2,3}$ \\ ${ }^{1}$ Occupational and Environmental Health Center, Clalit Health Services, Tel-Aviv, Israel \\ ${ }^{2}$ The Sackler Faculty of Medicine, Tel-Aviv University, Tel-Aviv 69978, Israel \\ ${ }^{3}$ National Lab Service for ILD, Institute of Pulmonary and Allergic Diseases, Tel-Aviv Sourasky Medical Center, Tel-Aviv 64239, Israel
}

Received 13 October 2005; Accepted 12 December 2005

\begin{abstract}
We investigated whether metalloproteinase-9 (MMP-9) values in induced sputum (IS) and pulmonary function tests can serve as a marker of damage and intensity of exposure to hazardous dust. Thirty-nine factory employees (28 workers exposed to metal particles and 11 supposedly nonexposed office workers) underwent IS induction. Samples were processed by conventional methods within 2 hours. The proportion of particles with diameters of $0-2 \mu$ in IS samples was significantly higher in nonexposed than exposed workers and in smoker compared to nonsmoker workers. MMP-9 and TIMP-1 levels were similar for both groups. A linear regression model for MMP-9 based on exposure, smoking habits, and proportion of particles $<5 \mu$ revealed a positive correlation between each of the explanatory variables and MMP-9 values. MMP-9 may serve as a marker for pulmonary injury.
\end{abstract}

Copyright (c) 2006 Yehuda Lerman et al. This is an open access article distributed under the Creative Commons Attribution License, which permits unrestricted use, distribution, and reproduction in any medium, provided the original work is properly cited.

\section{INTRODUCTION}

Inhalation of certain types of inorganic dust can be associated with reversible pulmonary inflammation as well as the induction of an irreversible inflammatory and fibrotic lung response. Some mediators, such as cytokines and growth factors, have been implicated in pulmonary inflammation characterized by the recruitment of inflammatory cells into the alveolar compartment [1-3]. The airways are ultimately subjected to a prolonged chronic inflammatory state that leads to a number of structural abnormalities. We selected matrix metalloproteinases (MMPs) as markers for this state insofar as they are key enzymes involved in extracellular matrix (ECM) degradation in physiological and pathological conditions.

MMPs consist of a number of structurally related enzymes capable of digesting ECM and basement membrane components [4]. The gelatinases MMP-2 and MMP-9 have a substrate affinity for basement membrane type IV collagen, denatured collagens (gelatin), and elastin. The tissue inhibitors of metalloproteinases (TIMPs) comprise a family of which four members have thus far been identified: they form complexes with active enzymes and inhibit MMP activity [5].

We recently reported that IS may reveal the status of hazardous dust exposure (silica and hard metals) as effectively as bronchoalveolar lavage (BAL) [6]. BAL and IS specimens among silica and hard metal workers yielded similar quantitative and qualitative results in mean numbers and size distribution of particles present in samples and chemical analysis of the retrieved particles. In a subsequent study, we demonstrated that distribution of particles size in IS specimens was different between exposed and nonexposed workers, and that there was a correlation between the distribution of particle size and the results of these workers' pulmonary function tests [7]. We also showed that metalloproteinase-9 (MMP-9) is elevated in the IS of patients with granulomatous diseases [8].

In the present study, we evaluated the inflammatory role of MMP-9 in the airways of workers directly exposed to hazardous dust in order to detect occult pulmonary pathology. We compared our findings to those of a group of workers in offices of the same plant and whom we assumed were not similarly exposed to these particles.

\section{METHODS}

\section{Study population}

Twenty-eight male employees in a steel production factory volunteered to participate in the study which was approved by the Tel Aviv Sourasky Medical Center Ethics Committee. Their jobs consisted of constructing patterns for assembling 
molds by melting, refining, and pouring the metal into molds and finally removing all adherent sand and superfluous metal from the finished casting. The molds were made of silica sand bound with clay. All of the subjects were actively employed and exposed to silica, chromium ferrum, nickel, and silicone. What we had considered as being a "nonexposed" group consisted of 11 office workers in the same plant.

The respective range and median of exposure, as measured by environmental monitoring of airborne particles in the factory, were $0.04-50.76 \mathrm{mg} / \mathrm{m}^{3}$ and $4.1 \mathrm{mg} / \mathrm{m}^{3}$ for iron oxides (threshold limit value $(\mathrm{TLV})=5 \mathrm{mg} / \mathrm{m}^{3}$ ), 0.0009$0.26 \mathrm{mg} / \mathrm{m}^{3}$ and $0.032 \mathrm{mg} / \mathrm{m}^{3}$ for chromium $(\mathrm{TLV}=0.01$ $\left.\mathrm{mg} / \mathrm{m}^{3}\right), \quad 0.0083-0.86 \mathrm{mg} / \mathrm{m}^{3}$ and $0.076 \mathrm{mg} / \mathrm{m}^{3}$ for nickel $\left(\mathrm{TLV}=0.2 \mathrm{mg} / \mathrm{m}^{3}\right), 0.0074-0.84 \mathrm{mg} / \mathrm{m}^{3}$ and $0.091 \mathrm{mg} / \mathrm{m}^{3}$ for manganese $\left(\mathrm{TLV}=0.2 \mathrm{mg} / \mathrm{m}^{3}\right), 0.01-0.088 \mathrm{mg} / \mathrm{m}^{3}$ and 0.028 for respirable free crystalline silica (TLV $=0.1 \mathrm{mg} / \mathrm{m}^{3}$ ), and $0.04-2.58 \mathrm{mg} / \mathrm{m}^{3}$ and 0.29 for total free crystalline silica $\left(\mathrm{TLV}=0.3 \mathrm{mg} / \mathrm{m}^{3}\right)$.

\section{Data Collection}

Each participant in the study filled in a questionnaire on demographic and occupational parameters, smoking and alcohol consumption habits, a general health profile, and symptoms and signs specific to respiratory problems.

\section{Sputum induction and processing}

Sputum induction was performed at the workplace using a slightly modified method of Pin et al [9], and the retrieved material was brought to the laboratory for analysis within two hours of induction, with no need for refrigeration. After pretreatment with a short-acting beta-2 agonist, 3\% saline was administered by a nebulizer (U1 Ultrasonic Nebulizer, Omron HealthCare, New Barn Lane, Henfield West Sussex, USA) for up to 20 minutes while the subjects were encouraged to cough and expectorate sputum into a sterile container. Samples were stored at $4^{\circ} \mathrm{C}$ and processed within 3 hours. All portions with little or no squamous epithelial cells (rich nonsquamous epithelial cell fraction considered to originate from the lower respiratory tract, hereafter referred to as "plugs") were collected using the "selection plug method" and processed as previously described $[6,10]$. Briefly, plugs were selected and treated with dithiothreitol (DTT; Sputalysin, Calbiochem Corp, San Diego, Calif, USA). The cell suspension was filtered through a $52-\mu \mathrm{m}$ nylon gauze (BNSH Thompson, Scarborough, Ontario, Canada) and the effect of DTT was stopped by diluting the suspension with phosphate-buffered solution (PBS) to a volume equal to the sputum plus DTT. After centrifugation, the supernatants were deep frozen for consecutive measurement of MMP-9. The pellets were resuspended and cytospinned (Shandon Southern Instruments, Sewickley, Pa, USA), and the slides were stained by Giemsa. Two-hundred nonsquamous cells were counted, and the results were expressed as a percentage of the total nonsquamous count. The slides were read by two independent readers.

\section{Quantitative analysis}

Particle size analysis (PSA) and dynamic shape characterization (DSC) were performed by employing a laser technique based on the time of transition (TOT) theory [11] using a CIS-1 Analyzer (Ankersmid-Yokneam, Israel). This method allows an exact quantitative analysis to be obtained according to particle size. The range diameter of the particles that were measured was $0.5-10 \mu \mathrm{m}$. Two drops of a suspension of sputum cells $\left(10^{6}\right.$ cells $\left./ \mathrm{ml}\right)$ were introduced into a quartz cuvette containing stirred X3 distilled water. A HeNe laser beam crossed the particles suspension and the signal was registered by a photodiode placed directly behind them. A control background was obtained with X3 distilled water with no measurable particles.

For comparison of their sizes, we divided the particles into four groups according to their diameters, that is, $<2 \mu$, $>2 \mu$, between $2-5 \mu$, and $>5 \mu$.

\section{Spirometry}

Spirometry was performed by a portable spirometer (Vitalograph-compact II, Buckingham, UK). Measurements followed standard protocols according to the American Thoracic Society guidelines [12]. The best of three consecutive measurements was chosen.

\section{MMP-9 and TIMP-1 levels}

The absolute value of MMP-9 in the IS samples was obtained by enzyme-linked immunoabsorbent assay (ELISA, R \& D Systems Inc, Minn, USA). The normal range for MMP-9 is $0.17-0.39 \mathrm{ng} / \mathrm{ml}$ and for TIMP-1 is $0-0.40 \mathrm{ng} / \mathrm{ml}$ [8].

\section{Statistical analysis}

Comparisons between the groups of subjects (exposed versus nonexposed, smokers versus nonsmokers) with regard to demographic and clinical factors were performed using t-tests for independent samples, Mann-Whitney nonparametric test, Chi-square and Fisher's Exact tests, as applicable. Pearson correlation coefficients were calculated to study the relationship between particle diameter size and spirometry parameters in the entire sample and in each subgroup separately, according to smoking habits and metals exposure. A multiple linear regression analysis was performed to evaluate the simultaneous effect of smoking habits, extended exposure, and proportions of particles on the inflammatory response as measured by MMP-9. The assessment of goodness of fit of the model was done using $R^{2}$. The statistical significance level was set to 0.05 and the SPSS for Windows software, Version 12.0 was used for the analysis.

\section{RESULTS}

Comparison of the demographic, occupational and medical history differences between the exposed and nonexposed 
TABLE 1: Demographic and occupational parameters of the study participants.

\begin{tabular}{lccc}
\hline & Exposed $(n=28)$ & Nonexposed $(n=11)$ & $P$-value* NS \\
\hline Age (years) mean \pm SD & $47.6 \pm 10.9$ & $51.4 \pm 6.6$ & 4 \\
Smokers $(n)$ & 22 & 7 & 0.022 \\
Nonsmokers $(n)$ & 6 & & - \\
\hline Employment at the present workplace & & $10.5 \%$ & - \\
\hline$<10$ years & $55.0 \%$ & $31.6 \%$ & - \\
$11-20$ years & $22.5 \%$ & $57.9 \%$ & 0.003 \\
$>20$ years & $22.5 \%$ & & - \\
\hline
\end{tabular}

NS: nonsignificant.

* Nonparametric Mann-Whitney test. A $P$-value <.05 was considered as indicative of a significant statistical difference.

TABLE 2: A comparison of particles size, spirometry parameters, MMP-9, and differential cell counts between the exposed, nonexposed, smoker, and nonsmoker groups.

\begin{tabular}{lcccc}
\hline & Exposed $n=28$ & Nonexposed $n=11$ & Smokers $n=26$ & Nonsmokers $n=13$ \\
\hline \% Particles with a 0-2 $\mu$ diameter & $91.8 \pm 4.9^{*}$ & $95.9 \pm 5.2^{*}$ & $95.4 \pm 5.2^{*}$ & $91.8 \pm 4.8^{*}$ \\
FVC(\%) & $91.9 \pm 10.6$ & $89.6 \pm 12.6$ & $89 \pm 12.7$ & $92.9 \pm 10.6$ \\
FEV1/FVC & $80.5 \pm 5.6^{*}$ & $85 \pm .26 .4^{*}$ & $84 \pm 7.3$ & $83 . \pm 4.4$ \\
Neutrophils (\%) & $42.8 \pm 27.9$ & $56.4 \pm 27.8$ & $61 \pm 22.6$ & $37.7 \pm 33.2$ \\
Lymph (\%) & $5.3 \pm 4.8$ & $13.8 \pm 23.1$ & $4.2 \pm 3.2$ & $13 \pm 18$ \\
Macroph (\%) & $42.6 \pm 30$ & $35.9 \pm 27.7$ & $32 \pm 22.6$ & $48.8 \pm 35.6$ \\
Eosinophils (\%) & $2.4 \pm 3.1$ & $1.3 \pm 0.8^{*}$ & $2.8 \pm 3.2^{*}$ & $0.5 \pm 1.41^{*}$ \\
MMP-9 (ng/ul) & $1.5 \pm 1.5$ & $1.3 \pm 1.2$ & $1.6 \pm 1.4$ & $0.13 \pm 0.02$ \\
TIMP-1 (ng/ul) & $0.16 \pm 0.02$ & $0.14 \pm 0.01$ & & $0.14 \pm 0.03$ \\
\hline
\end{tabular}

MMP-9: metalloproteinase-9, TIMP-1: tissue inhibitor metalloproteinase, NS: nonsignificant.

*Nonparametric Mann-Whitney test. A $P$-value $<.05$ was considered as indicative of a significant statistical difference.

groups showed no differences in age or in the presence of symptoms and signs of respiratory diseases. There were more smokers among the exposed workers $(p=0.022)$ who had also worked for a shorter period of time in the plant than among the nonexposed workers $(p=0.0030)$ (Table 1$)$.

A comparison of the particle sizes between the exposed and nonexposed groups revealed a significant difference in the proportion of particles with a diameter of $0-2 \mu$ : it was higher in the nonexposed workers $(91.8 \pm 4.9 \%$ versus $95.9 \pm$ $5.2 \%$, resp, $p=0.03$ ). Similar differences were found between particle sizes in smokers versus nonsmokers (95.4 \pm $5.2 \%$ versus $91.8 \pm 4.8 \%$, resp, $p=0.05)$. Pulmonary function tests showed a significant difference in the FEV1/FVC ratio (lower in the nonexposed group, $p=0.035$ ), but no difference in the FVC and FEV1 parameters (Table 2).

A positive strong correlation was found between the secretion of MMP-9 and TIMP-1 $(r=0.88 ; p=0.0000)$ in all measurements, but there were no differences in metabolite secretion when groups were divided according to exposure. The differential cell counts from IS samples showed a borderline difference between exposed and nonexposed workers, but the difference was significant between the smokers and nonsmokers $(2.8 \pm 3.2 \%$ in smokers versus $0.5 \pm 1.4 \%$ in nonsmokers $(p=0.013)$. There were no significant differences in any of the other cell types (Table 2). Measurable levels of MMP-9 and TIMP-1 were detected more in smokers samples than in nonsmokers samples $(p=0.046$ and $p=0.035$, resp).

The associations between MMP-9 and particle diameter size, pulmonary function tests and differential counts were checked using the Pearson correlation, dividing the workers according to length of exposure. Significant correlations were found only for the group of nonexposed workers: the correlation was positive between the percentage eosinophils and MMP-9 and negative between the PFT parameters and MMP-9 (Table 3).

In order to check what are the other factors that could be involved in inflammatory changes in nonexposed workers, a second group of correlations was performed after dividing the workers according to smoking status (Table 3 ). There was a positive correlation between percentage particles with a 0 $2 \mu$ diameter $(r=0.4, p=0.08)$ and a negative significant 
TABLE 3: Correlation of different parameters with MMP-9 (ng/ml) secretion among exposed and nonexposed workers.

\begin{tabular}{lcr}
\hline & Parameter & \multicolumn{2}{c}{ MMP-9 (ng/ml $)$} \\
& \multicolumn{1}{c}{ Pearson correlation $=r ;$ significance $=p$} & Nonexposed $(n=11)$ \\
\hline FEV1 $(\mathrm{L})$ & $r=0.1 ; p=0.5$ & $r=-0.7 ; p=0.016$ \\
FEV1/FVC & $r=0.04 ; p=0.8$ & $r=-0.8 ; p=0.002$ \\
Eosinophils $(\% n=26)$ & $r=-0.4 ; p=0.07$ & $r=0.8 ; p=0.047$ \\
\hline & Smokers $(n=26)$ & Nonsmokers $(n=13)$ \\
\hline \% Particles with a $0-2 \mu$ diameter & $r=0.356 ; p=0.08$ & $r=0.2 ; p=0.1$ \\
\hline
\end{tabular}

MMP-9: metalloproteinase-9.

A $P$-value $<.05$ was considered as indicative of a significant statistical difference.

TABLE 4: Linear regression model for MMP-9 based on exposure, smoking habits, and proportion of particles $\leq 5 \mu$ in diameter [total $\left.R^{2}=0.181, N=36\right]$.

\begin{tabular}{|c|c|c|c|}
\hline Parameter & B (CI 95\%) & $P$-value & $R^{2}$ \\
\hline$\%$ particles with $\mathrm{a} \leq 5 \mu$ diameter & $0.27(0.02,0.53)$ & 0.038 & 0.084 \\
\hline Smoking habits & $-0.86(-1.75,0.38)$ & 0.060 & 0.094 \\
\hline Exposure to metals & $0.17(-0.76,1.10)$ & 0.713 & 0.003 \\
\hline Constant & $-24.25(-49.1,0.60)$ & - & - \\
\hline
\end{tabular}

MMP-9: metalloproteinase-9.

correlation between particles $>5 \mu$ in diameter and MMP-9 levels in smokers $(r=0.4, p=0.05)$.

A linear regression model for MMP-9 based on exposure, smoking habits, and proportion of particles $\leq 5 \mu$ revealed a positive correlation between each one of these explanatory variables and MMP-9 (Model $R$-square $=0.18$ ), although the impact of exposure was not significant (Table 4).

\section{DISCUSSION}

In the present work, we assessed 28 workers who were exposed to airborne particles of silica and metals and 11 workers in the administration offices of the same plant: our expectation was that the latter would serve as a suitable control group. The results showed that our "control" group had significantly smaller particles in their IS samples, displayed an inflammatory pattern as indicated by a higher percentage of eosinophils in sputum and their FEV1/FVC values had a significant trend for lower ratios for obstructive and not restrictive disease as we had originally expected. The presence of a higher percentage of small particles, even to an apparently small degree, exerts a biological effect by increasing the level of eosinophils in sputum in correlation to physiological changes. This unexpected finding might be explained by the facts that the nonexposed workers were older and that most of them had worked at the factory for longer than 10 years. They had probably been indirectly exposed to dust at lower levels than their coworkers and for a longer period of time, which may underestimate the risks. It is known that there is usually a long latency period between the start of exposure and the appearance of clinical symptoms of an occupational lung disease, ranging anywhere between 10-30 years [13].

The MMP-9 and TIMP-1 levels were similar between the groups, but the picture became reversed when we compared the smokers among them: the smokers in the exposed and "control" group had more inflammatory parameters, as indicated by differential cell counts and MMP-9 measurements, than all the nonsmokers. Consequently, our next step was to assess the correlations of MMP-9 and TIMP-1 with exposure between smokers and nonsmokers in the entire cohort. We found a positive correlation between the inflammatory parameters, the percentage of small particles - and not the anticipated large particles-in the IS samples of the smokers.

Our working hypothesis was that MMP-9 levels would be elevated among workers exposed to mineral particles as a marker of early events occurring in profibrotic lesions. This hypothesis was based on the fact that MMPs and TIMPs were recently shown to participate in the parenchymal destruction and repair processes resulting in ECM remodeling, and to be involved with different pulmonary processes associated with the destruction of the subepithelial basement membrane, for example, idiopathic interstitial pneumonias [14] and pulmonary fibrosis [15]. Moreover, MMP-9 was found to be elevated in experimental lung silicosis [16] and in workers 
exposed to toluene diisocyanate [17]. The results we obtained did not support our working hypothesis, but rather raised the problematic issue of the exposure of workers who smoke in terms of the combined effect of smoking and occupational exposure.

The main contribution of the present study is the demonstration of what appears to be combined respiratory impairment due to smoking and occupational/environmental exposure among smoker workers. The levels of MMP-9 and TIMP-1 could be mainly explained by their smoking status. Indeed, a recent study investigated the release and activity of MMP-9 and of TIMP-1 from alveolar macrophages obtained from patients with COPD, and compared them with age and smoking status-matched healthy smokers. The results showed that alveolar macrophages are a significant source of MMP-9 in the airways of smokers subjects with COPD, and that they were more active than MMP-9 released from alveolar macrophages of healthy smokers and nonsmoking subjects [18].

Evidence from experimental models showed that the combination of exposure to particles plus ozone, cigarette smoke, or reagent hydrogen peroxide augments the inflammatory response, increases cell proliferation, and leads to liberation of increased levels of chemoattractant mediators. It is also known that particulate matter adheres and penetrates epithelial cells, that retention within the walls of small airways is increased by cigarette smoke, and that long-term exposure to high levels of ambient particulate pollutants is associated with small airway remodeling, even in nonsmokers [19]. This potent mixture contained in cigarettes, therefore, exhibits major effects on the airway and may contribute to alteration of the MMP/TIMP balance, a process that may produce chronic airflow obstruction [20]. We now report the association of MMP-9 and TIMP-1 in IS in correlation to combined particle burden from smoking and occupational exposure in the work plant.

We concluded from the findings of this study that there is a need to include all workers in a plant in screening and medical follow-up programs, even those not directly related to the manufacturing process. Having shown that MMP-9 levels are high in apparently healthy exposed workers, we consider this enzyme as representing an interesting compound that merits further studies in other forms of pulmonary disease.

\section{ACKNOWLEDGMENTS}

We thank Esther Eshkol for her excellent editorial assistance. This study was supported by grants from the Manof Fund of the National Insurance Institute, Israel, and the Committee for Research and Prevention in Occupational Safety and Health, Ministry of Labor, Israel.

\section{REFERENCES}

[1] Warshamana GS, Pociask DA, Sime P, Schwartz DA, Brody AR. Susceptibility to asbestos-induced and transforming growth factor- $\beta_{1}$-induced fibroproliferative lung disease in two strains of mice. American Journal of Respiratory Cell and Molecular Biology. 2002;27(6):705-713.
[2] Ortiz LA, Lasky J, Lungarella G, et al. Upregulation of the p75 but not the p55 TNF- $\alpha$ receptor mRNA after silica and bleomycin exposure and protection from lung injury in double receptor knockout mice. American Journal of Respiratory Cell and Molecular Biology. 1999;20(4):825-833.

[3] Liu JY, Morris GF, Lei WH, Corti M, Brody AR. Upregulated expression of transforming growth factor-alpha in the bronchiolar-alveolar duct regions of asbestos-exposed rats. The American Journal of Pathology. 1996;149(1):205-217.

[4] Gómez DE, Alonso DF, Yoshiji H, Thorgeirsson UP. Tissue inhibitors of metalloproteinases: structure, regulation and biological functions. European Journal of Cell Biology. 1997;74(2):111-122.

[5] Woessner JF Jr. The family of matrix metalloproteinases. Annals of the New York Academy of Sciences. 1994;732:11-21.

[6] Fireman E, Greif J, Schwarz Y, et al. Assessment of hazardous dust exposure by BAL and induced sputum. Chest. 1999;115(6):1720-1728.

[7] Lerman Y, Segal B, Rochvarger M, Weinberg D, Kivity O, Fireman E. Induced-sputum particle size distribution and pulmonary function in foundry workers. Archives of Environmental Health. 2003;58(9):565-571.

[8] Fireman E, Kraiem Z, Sade O, Greif J, Fireman Z. Induced sputum-retrieved matrix metalloproteinase 9 and tissue metalloproteinase inhibitor 1 in granulomatous diseases. Clinical and Experimental Immunology. 2002;130(2):331-337.

[9] Pin I, Gibson PG, Kolendowicz R, et al. Use of induced sputum cell counts to investigate airway inflammation in asthma. Thorax. 1992;47(1):25-29.

[10] Popov T, Gottschalk R, Kolendowicz R, Dolovich J, Powers P, Hargreave FE. The evaluation of a cell dispersion method of sputum examination. Clinical \& Experimental Allergy. 1994;24(8):778-783.

[11] Aharonson A, Karasikov N, Krauss M, et al. Measurement of particle size in the range of $150-1200 \mu$ using the TOT method. Journal of Aerosol Science. 1986;17:530-536.

[12] Standardization of spirometry-1987 update. Statement of the American Thoracic Society. The American Review of Respiratory Disease. 1987;136(5):1285-1298.

[13] Weber SL, Banks DE. Silicosis. In: Rosenstock L, Cullen MR, eds. Textbook of Occupational and Environmental Medicine. Philadelphia, Pa: W.B. Saunders; 1994:266-267.

[14] Suga M, Iyonaga K, Okamoto T, et al. Characteristic elevation of matrix metalloproteinase activity in idiopathic interstitial pneumonias. American Journal of Respiratory and Critical Care Medicine. 2000;162(5):1949-1956.

[15] Ruiz V, Ordóñez RM, Berumen J, et al. Unbalanced collagenases/TIMP-1 expression and epithelial apoptosis in experimental lung fibrosis. American Journal of Physiology. Lung Cellular and Molecular Physiology. 2003;285(5):L1026-L1036.

[16] Pérez-Ramos J, de Lourdes Segura-Valdez M, Vanda B, Selman M, Pardo A. Matrix metalloproteinases 2, 9, and 13, and tissue inhibitors of metalloproteinases 1 and 2 in experimental lung silicosis. American Journal of Respiratory and Critical Care Medicine. 1999;160(4):1274-1282.

[17] Park H-S, Kim H-A, Jung J-W, et al. Metalloproteinase-9 is increased after toluene diisocyanate exposure in the induced sputum from patients with toluene diisocyanate-induced asthma. Clinical \& Experimental Allergy. 2003;33(1):113-118.

[18] Russell REK, Culpitt SV, DeMatos C, et al. Release and activity of matrix metalloproteinase- 9 and tissue inhibitor of metalloproteinase- 1 by alveolar macrophages from patients with chronic obstructive pulmonary disease. American Journal of Respiratory Cell and Molecular Biology. 2002;26(5):602-609. 
[19] Churg A. Interactions of exogenous or evoked agents and particles: the role of reactive oxygen species. Free Radical Biology and Medicine. 2003;34(10):1230-1235.

[20] Churg A, Brauer M, del Carmen Avila-Casado M, Fortoul TI, Wright JL. Chronic exposure to high levels of particulate air pollution and small airway remodeling. Environmental Health Perspectives. 2003;111(5):714-718. 


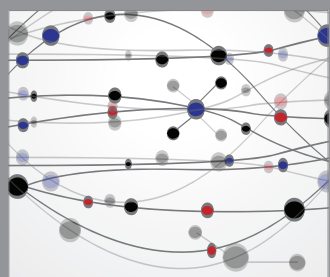

The Scientific World Journal
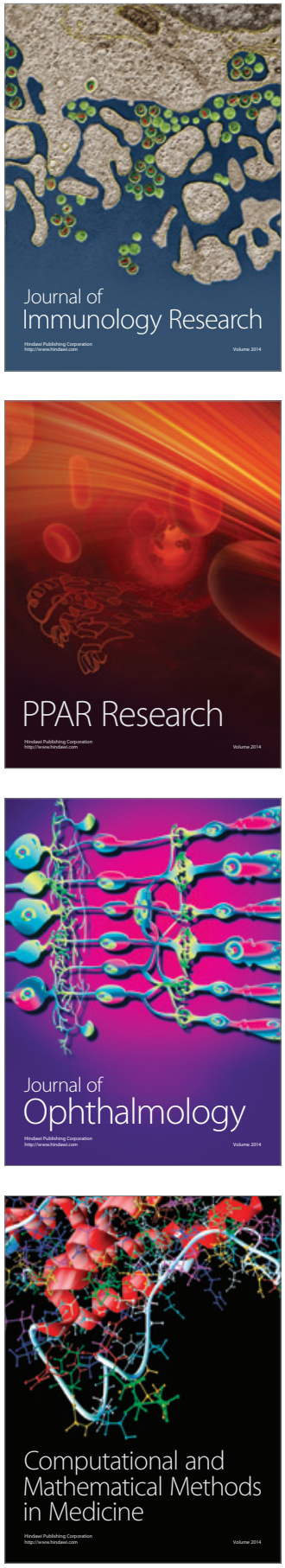

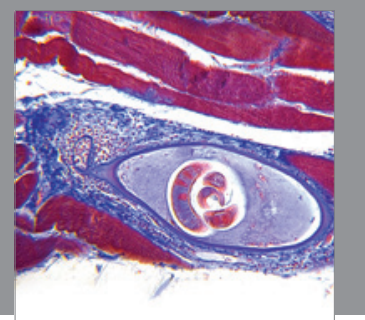

Gastroenterology

Research and Practice
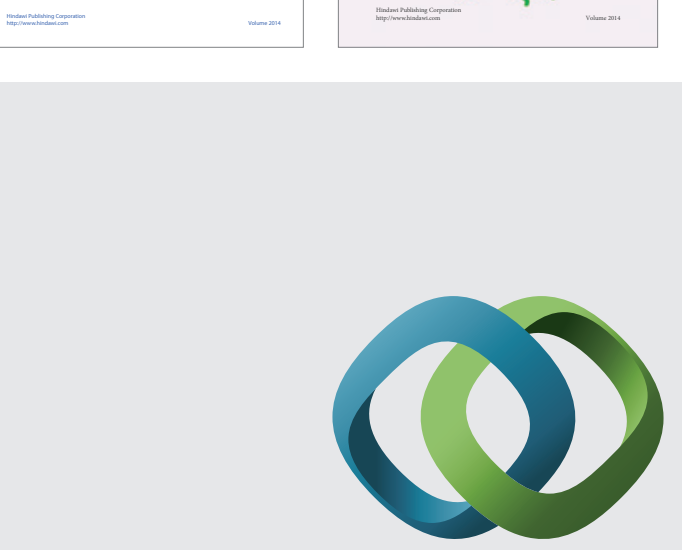

\section{Hindawi}

Submit your manuscripts at

http://www.hindawi.com
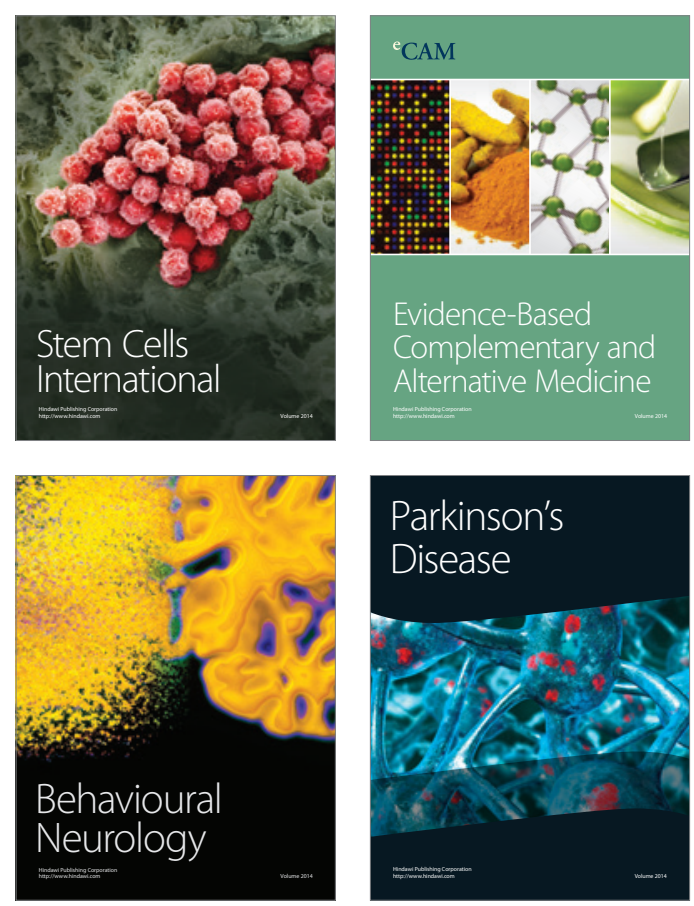

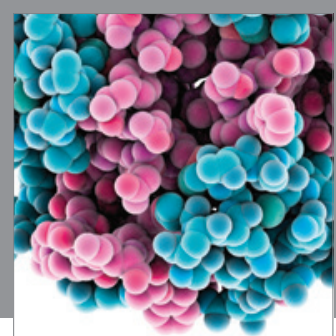

Journal of
Diabetes Research

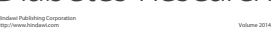

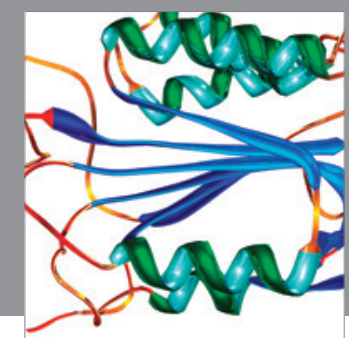

Disease Markers
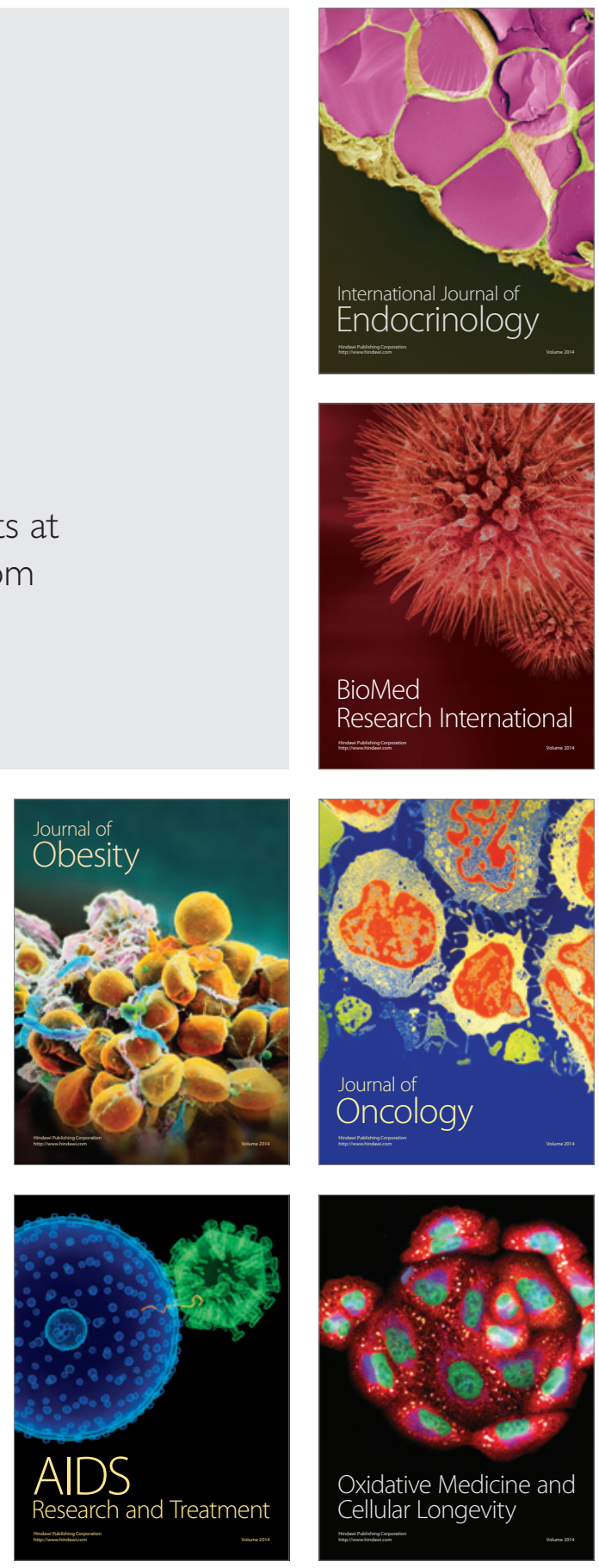